\title{
A CASE REPORT OF PRIMARY LUMBAR HERNIA- SELDOM SEEN BY SURGEONS
}

\author{
Mohamed Musthafaํ, Parivallal Damodaran², Sadasivam Prakash ${ }^{3}$, Yella Surya Kiran ${ }^{4}$
}

1Professor, Department of General Surgery, SRM Medical College Hospital and Research Centre, Kattankulathur, Kanchipuram, Tamilnadu.

2Postgraduate Student, Department of General Surgery, SRM Medical College Hospital and Research Centre, Kattankulathur, Kanchipuram, Tamilnadu.

${ }^{3}$ Assistant Professor, Department of General Surgery, SRM Medical College Hospital and Research Centre, Kattankulathur, Kanchipuram, Tamilnadu.

${ }^{4}$ Postgraduate Student, Department of General Surgery, SRM Medical College Hospital and Research Centre, Kattankulathur, Kanchipuram, Tamilnadu.

HOW TO CITE THIS ARTICLE: Musthafa M, Damodaran P, Prakash S, et al. A case report of primary lumbar hernia- seldom seen by surgeons. J. Evolution Med. Dent. Sci. 2018;7(17):2165-2166, DOI: 10.14260/jemds/2018/485

\section{CASE PRESENTATION}

A 54-year-old moderately built gentleman presented to surgery OPD with complaints of swelling over the left lumbar region for the past 5 months associated with dull aching left sided abdominal pain for the past one month. There was no previous history of trauma, abdominal surgeries, fever, weight loss or any associated bowel or urinary complaints. Patient is a known case of bronchial asthma, diabetes mellitus and systemic hypertension on regular medications.

On examination there was $6 \mathrm{X} 5 \mathrm{cms}$ soft, swollen, not tender, partially reducible mass with impulse on cough below the left costal margin, lateral to dorsolumbar spine. Opposite side lumbar region and other hernial orifices were normal.

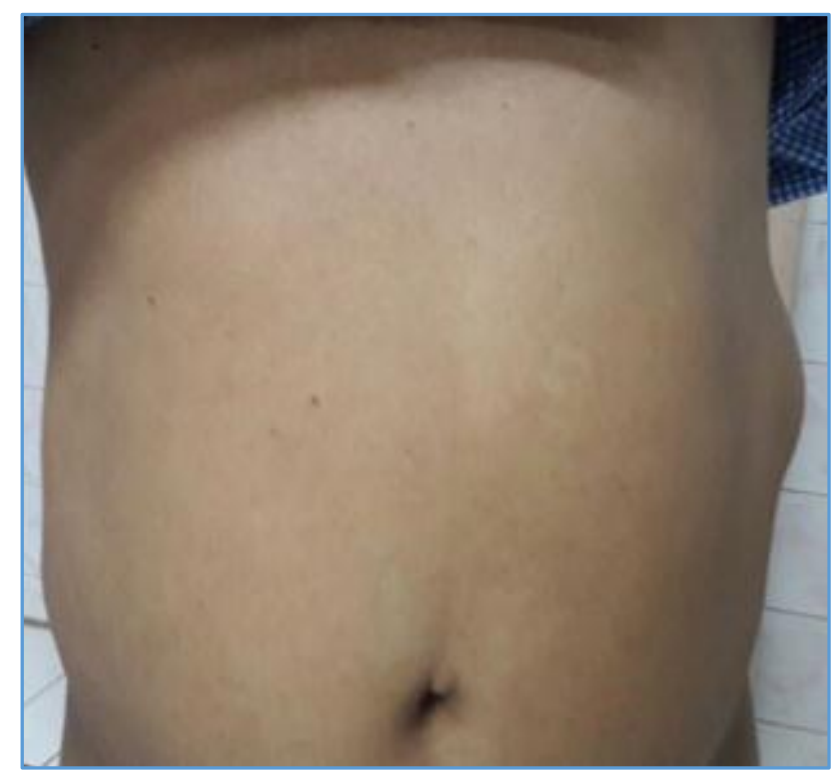

Figure 1. Pre-operative image of left lumbar hernia

'Financial or Other Competing Interest': None.

Submission 13-03-2018, Peer Review 05-04-2018,

Acceptance 12-04-2018, Published 23-04-2018.

Corresponding Author:

Parivallal Damodaran,

M-402, Abade Valley,

Kakkar Street, Potheri-603203,

Kanchipuram District,

Tamilnadu.

E-mail: pari_vallal69@yahoo.com

DOI: $10.14260 /$ jemds $/ 2018 / 485$

(c) (i) $(5)$
His complete haemogram and renal function test showed normal values. His ECG, $\mathrm{X}$ ray chest and plain abdomen $\mathrm{x}$ ray were within normal limits. Ultrasonography of Abdomen showed herniation of retroperitoneal fat in the inter muscular space over the left lumbar region. CT abdomen plain revealed herniation of retroperitoneal fat with thinning and dehiscence of inner layer of muscles of left lumbar region - suggestive of left lumbar hernia.

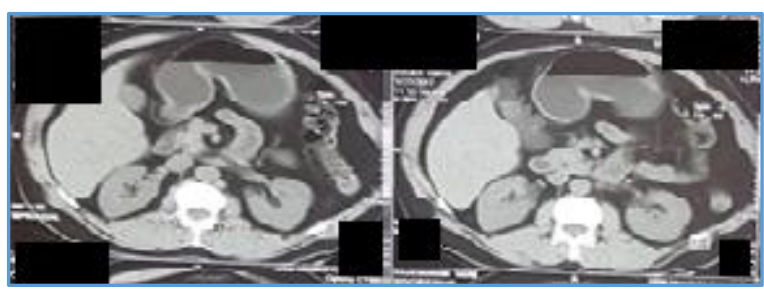

Figure 2. CT abdomen plain - axial view showing left lumbar hernia

\section{DIFFERENTIAL DIAGNOSIS}

- lipoma,

- Fibroma,

- Muscle hernia,

- Cold abscess,

- Hematomas,

- Panniculitis or

- Intra-abdominal / Retroperitoneal tumours.

\section{CLINICAL DIAGNOSIS}

A diagnosis of primary left lumbar hernia was made based on clinical and radiological imaging.

\section{DISCUSSION OF MANAGEMENT}

Patient planned for elective surgery - open left lumbar hernioplasty / herniorrhaphy. Anaesthetic assessment and consent obtained for surgery. The hernia was approached through left lumbar region. Intra operatively, content found to be retroperitoneal fat (Image 1) with defect of size $4 \times 3$ $\mathrm{cm}$ with thinned out fascia noted in superior lumbar triangle. Content reduced to retro peritoneum. Sublay repair was carried out with polypropylene mesh placed in pre-peritoneal space (Image 2) and defect approximated using prolene suture. Post-operative period was uneventful. On regular followup for 1 year no recurrence noted. 


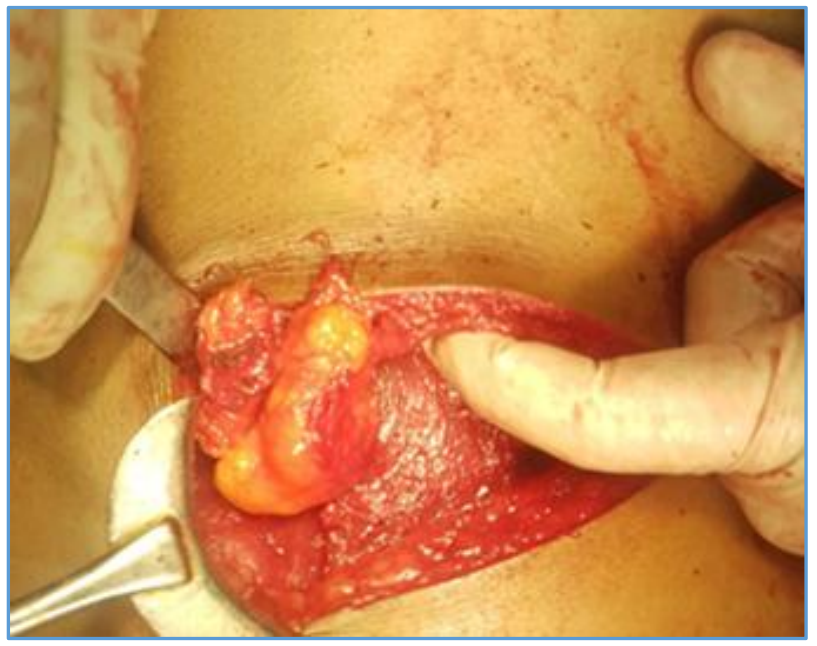

Image 1. Defect noted in the left superior lumbar triangle with retroperitoneal fat as content

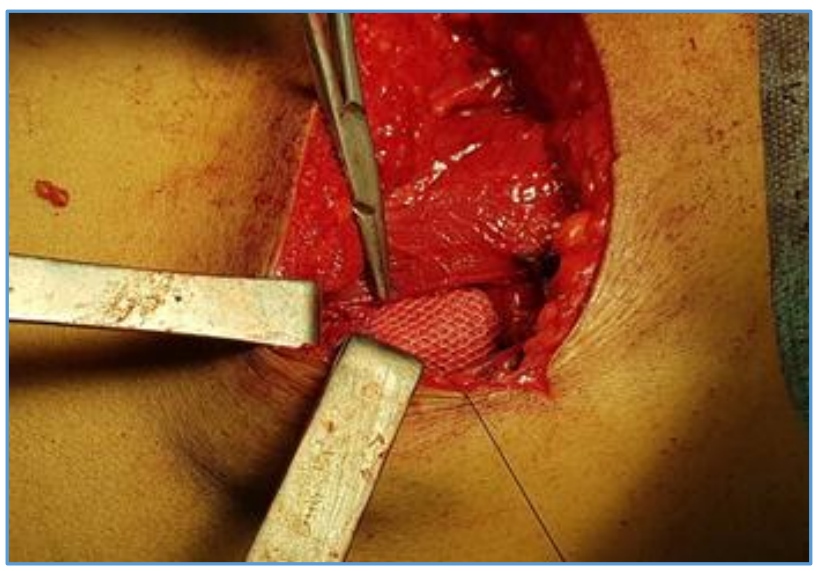

Image 2. Sublay Mesh in place

Lumbar hernia was first described by Barbette in 1672 and R.J.C Garangeot published a case for the first time in 1731 1. Since then, only about 300 cases have been reported ${ }^{1}$. In 1750, H. Ravaton performed first surgery for a strangulated lumbar hernia in a pregnant woman. The surgical anatomy of the inferior lumbar space was made by Petit in 1783 and description of the superior lumbar space was made by Grynfeltt in 1866. In 1916, Goodman pointed out the predominance of the inferior space as the most common site of lumbar hernia but studies after 1920 show that superior location is more common.

Lumbar hernia manifest through two possible defects in the posterior abdominal wall- superior and inferior lumbar triangle. The larger superior triangle is inverted, deeper and more constant. The superior lumbar region is bounded superiorly by the $12^{\text {th }}$ rib, medially by the erector spinae muscles, inferiorly by the iliac crest bone, laterally by the external oblique muscles, floor is by transversalis fascia and roof formed by latissimus dorsi muscles. Inferior lumbar space is bordered by iliac crest inferiorly, external oblique muscle laterally and latissimus dorsi muscle ${ }^{2}$, medially.

Lumbar hernia may be $20 \%$ congenital or $80 \%$ acquired. An acquired may be primary or secondary. Secondary lumbar hernias are of traumatic or post-surgical (Flank incisions) aetiology comprising about $25 \%$ of acquired hernias. Congenital hernias have been noted to arise from inferior triangle and are often seen with other anomalies like renal agenesis, lumbocostovertebral syndrome ${ }^{3}$.

Ultrasonogram and CT remain investigations of choice and also MRI has a role in diagnosing and planning for surgical management. Surgical treatment is the only option and it should be considered early to avoid complications like irreducibility, incarceration and strangulation ${ }^{4}$. Earlier, most of the lumbar hernias were repaired primarily using muscle flaps from gluteus major and medius muscle, latissimus dorsi muscle and fascia lata. But the recurrence rate was very high due to poor fascial strength and high tension of repair. Later, artificial mesh with polypropylene, Marlex, or prolene was used to bridge the defect. The Dowd - Ponka technique of repairing lumbar hernia involves making an incision over hernia site and reducing the contents of the abdomen, followed by covering the defect with prosthetic mesh which is sutured to external oblique, latissimus dorsi and the lumbar periosteum. This is followed by constructing a gluteal fascial flap to cover the defect approximating external oblique and latissimus dorsi muscle 5 . In 1996, the first transabdominal laparoscopic approach was introduced by Burick and Parascandola ${ }^{6}$. There is no current recommendation for the use of any particular technique, though laparoscopic surgery has less morbidity, less pain and shorter hospital stay. Treatment choice has to be tailored to a particular patient in terms of defect location, size, content, status of surrounding tissues and patient affordability

\section{FINAL DIAGNOSIS}

Lumbar hernia are rare; good history and general physical examination is important to rule out most of the differential diagnoses. CT scan remains investigation of choice. Consider early surgery to avoid complications. This report describes the successful repair of the primary lumbar hernia using open tension free sub lay prosthesis with no recurrence on follow up.

\section{REFERENCES}

[1] Moreno-Egea A, Baena EG, Calle MC, et al. Controversies in the current management of lumbar hernias. Arch Surg 2007;142(1):82-8.

[2] Javid PJ, Brooks DC. Hernias. In: Zinner MJ, Ashley SW, (eds). Maingot's abdominal operations. $11^{\text {th }}$ edn. The McGraw-Hill Companies, 1997:163-4.

[3] Lillie GR, Deppert E. Inferior lumbar triangle hernia as a rarely reported cause of low back pain: a report of 4 cases. J Chiropr Med 2010;9(2):73-6.

[4] Swartz DWT. Lumbar hernia. In: Nyhus LM, Condon RE, (eds). Hernia. $2^{\text {nd }}$ edn. Lippincott; Philadelphia: 1978:409-26.

[5] Skandalakis LJ, Skandalakis JE, Skandalakis PN. Surgical anatomy and technique. $3^{\text {rd }}$ edn. Springer; 2008.

[6] Burick AJ, Parascandola SA. Laparoscopic repair of a traumatic lumbar hernia: a case report. J Laparoendosc Surg 1996;6(4):259-62. 